\title{
The European Journal of Ageing and the memorable year 2018
}

\author{
Marja J. Aartsen ${ }^{1}$ - Matthias Kliegel ${ }^{2} \cdot$ Morten Wahrendorf $^{3} \cdot$ Nadia Minicuci $^{4} \cdot$ Susanne Iwarsson $^{5}$
}

Published online: 18 February 2019

(c) Springer Nature B.V. 2019

\section{EJA, and how it all started}

The year 2018 was memorable for the European Journal of Ageing: Social Behavioral and Health Perspectives (EJA). After almost 15 years of inspiring leadership, the founding editors Dorly Deeg and Hans-Werner Wahl turned over their responsibilities for EJA to a new team of Editors-inchief, namely Marja Aartsen, Susanne Iwarsson and Matthias Kliegel. The first editorial in the very first issue of EJA (Deeg and Wahl 2004) radiated the excitement and enthusiasm with which Dorly and Hans-Werner had been looking forward to the birth of their brainchild EJA and showed how "happy and proud" they were when EJA first appeared. That editorial makes you realize the grandness of the founding editors' step to entrust their child to a new group of editors.

It all began with a simple unsuspecting comment-or a side note as they called it-between Dorly and Hans-Werner. However, "the journal virus was in them and became more and more virulent over time" (Deeg and Wahl 2004 p. 2). After a thorough desk research of the "existing ageing research journal landscape" and a market survey at the European Congress of Gerontology in Barcelona, July 2003, they felt that the time was ripe for a new interdisciplinary journal on ageing research in Europe (Deeg and Wahl 2004). The scientific mission they then formulated is still valid in 2019 (see Table 1). The end of the 1990s and the beginning of 2000 had witnessed a growing volume of interdisciplinary research on ageing in Europe, and with that came the increasing need for dissemination. Sure, there were excellent journals on ageing in the field of biology, geriatrics and

Marja J. Aartsen

maraar@oslomet.no

1 NOVA Norwegian Social Research, OsloMet - Oslo Metropolitan University, Oslo, Norway

2 Université de Genève, Genève, Switzerland

3 University of Düsseldorf, Düsseldorf, Germany

4 CNR, Neuroscience Institute, Padua, Italy

5 Lund University, Lund, Sweden rehabilitation at that time in Europe, but none of these had an interdisciplinary approach.

To further improve the quality of the journal, Dorly and Hans-Werner added a third editor-in-chief, Howie Litwin, who took the lead for submissions with a major focus on the social sciences (Wahl and Deeg 2013). Howie was involved as editor from 2012 to 2017 . With the careful dedication of these three editors, the number of new submissions grew from 100 in 2011 to more than 250 in 2018. The first Open Access paper of EJA appeared in the fourth year of EJA's existence, and 68 Open Access papers followed in the years thereafter. The former editors welcomed research from Eastern European and African countries, and there is a continuously growing number of submissions from these and other parts of the world. The number of such papers, though, that reaches publication quality is still low (Deeg et al. 2018). Some countries only recently entered the scientific stage, and scientific progress may be hindered by a lack of research funding. Hence, they still need to establish solid ageing research that is of interest for international publication. Open Access may be a good way to stimulate such research and to provide equal access to scientific publications for those who cannot afford the subscription fees. The high number of downloads of the 68 Open Access EJA papers (120,000 downloads in total) suggests that there is indeed a need for free access to journal articles.

\section{EJA, where next?}

And here we are; three new editors with this impressive EJA heritage, challenged by the task to keep the journal in good shape, guide it to an even greater maturity and serve as a platform for researchers on ageing from all over Europe and beyond. Already in 1961, Havighurst argued that "one of the major aims of gerontology is to provide society and individuals with advice on the making of societal and individual choices ..." (Havighurst 1961, p. 8). We agree that a thorough knowledge of the micro-, meso- and macro-level factors constructing the individual's life course, groups and 
Table 1 Mission statement for EJA

The European Journal of Ageing is an interdisciplinary journal devoted to the understanding of ageing in European societies and the world over. It publishes original articles on the social, behavioral and health-related aspects of ageing and encourages an integrated approach between these aspects. Emphasis is put on publishing empirical research (including meta-analyses), but conceptual papers (including narrative reviews) and methodological contributions will also be considered. The Journal welcomes expert opinions on critical issues in ageing. By stimulating communication between researchers and those using research findings, it aims to contribute to the formulation of better policies and the development of better practice in serving older adults

societies is indeed essential for policy makers, practitioners and eventually the older individual. Our ambition is that EJA will contribute with solid, high-quality research with analytical rigour to debug the myths of ageing, provide new directions for conflicting research outcomes and fill relevant knowledge gaps in the interdisciplinary ageing research field.

To handle the still growing numbers of new submissions, we recently extended our team of editors with an associate editor Dr. Morten Wahrendorf, University of Düsseldorf, Germany, as well as a statistical advisor Dr. Nadia Minicuci, Neuroscience Institute (CNR) in Padova, Italy. Morten's expertise is on working conditions and health, health inequalities, retirement, labour market participation and country comparisons. Nadia is our consultant when we need expertise advice on statistical matters, for example, with respect to structural equation models, data harmonizing, causal modelling and even Bayesian networks.

It is our hope and ambition to increase the number of publications from all European countries and continents worldwide in the years to come. We will continue with special sections, as we did in the past, for example, with Grandparenthood in Europe (Glaser and Hank 2018) Transnational ageing (Horn and Schweppe 2017) and Ageism (Ayalon and Tesch-Römer 2017). A number of special sections are foreseen, of which the first will be on sexuality among older adults and the other on views on ageing. Moreover, we hope to publish an increasing number of cross-national studies, as comparing different societies and cultures is crucial for the analysis of societal and cultural influences on the individual life course, and development of groups and society (TeschRömer and von Kondratowitz 2006). In particular, we hope to increase the number of contributions from Eastern European countries, as much can be learned from countries with different welfare regimes.

\section{Thank you}

We are extremely dependent on and very grateful to all colleagues who contribute to the journal as reviewers. Without such expert contributions, EJA could not exist. Yet, finding the right reviewers who are willing and able to review is an increasingly time-consuming task. Many potential reviewers have already committed themselves to the review of one or more papers for different journals. We feel an increasing need to find ways to recognize reviewers for their continuous effort to support EJA. This, of course, would need a system that guarantees the reviewer's anonymity.

Finally, we want to express our sincere thanks to Dorly Deeg and Hans-Werner Wahl, the founding editors of EJA, for the side note some 16 years ago about starting an interdisciplinary European journal on ageing. As with the butterfly that flaps its wings and causes a hurricane, so did these words, which led us to the well-established European Journal of Ageing: Social Behavioral and Health Perspectives.

\section{References}

Ayalon L, Tesch-Römer C (2017) Taking a closer look at ageism: selfand other-directed ageist attitudes and discrimination. Eur J Ageing 14:1-4

Deeg DJH, Wahl HW (2004) A new ageing research journal: introducing the European Journal of Ageing. Eur J Ageing 1:1-5

Deeg DJH, Wahl H-W, Litwin H (2018) Ageing and transitions: looking back and looking forward. Eur J Ageing 1:1-3

Glaser K, Hank K (2018) Grandparenthood in Europe. Eur J Ageing 15:221-223

Havighurs RJ (1961) Successful aging. Gerontologist 1:8-13

Horn V, Schweppe C (2017) Transnational aging: toward a transnational perspective in old age research. Eur J Ageing 14:335-339

Tesch-Römer C, von Kondratowitz HJ (2006) Comparative ageing research: a flourishing field in need of theoretical cultivation. Eur J Ageing 3:155-167

Wahl HW, Deeg DJH (2013) Celebrating volume 10 of the European journal of ageing. Eur J Ageing 10:1-2

Publisher's Note Springer Nature remains neutral with regard to jurisdictional claims in published maps and institutional affiliations. 